\title{
Expression of the Viral Antigen VP60 in Transgenic Potatoes and Its Effect on the Nutritional Composition of Tubers
}

\author{
Heike Mikschofsky ${ }^{1 *}$, Anja Hartmann ${ }^{2}$, Pawel Janczyk ${ }^{3}$, Günther M. Keil ${ }^{4}$, Patricia König ${ }^{4}$, \\ Horst Schirrmeier ${ }^{4}$, Martin Hammer ${ }^{4}$, Holger Junghans ${ }^{5}$, Kerstin Schmidt ${ }^{6}$, Jörg Schmidtke ${ }^{6}$, \\ Wolfgang B. Souffrant ${ }^{3}$, Manfred Schwerin ${ }^{2}$, Inge Broer ${ }^{1}$
}

\footnotetext{
${ }^{1}$ Agrobiotechnologie, Universität Rostock, Justus-von-Liebig-Weg, Germany; ${ }^{2}$ Research Group Functional Genomics, Research Institute for the Biology of Farm Animals Dummerstorf, Germany; ${ }^{3}$ Research Group Nutritional Physiology, Research Institute for the Biology of Farm Animals Dummerstorf, Germany; ${ }^{4}$ Friedrich-Loeffler-Institut, Südufer, Greifswald-Insel Riems, Germany; ${ }^{5}$ Norika GmbH, Parkweg, Groß Lüsewitz, Germany; ${ }^{6}$ BioMath GmbH, Thünenplatz, Groß Lüsewitz, Germany.

E-mail: Heike.Mikschofsky@uni-rostock.de

Received September 23 $3^{\text {rd }}, 2010$; revised February $24^{\text {th }}, 2011$; accepted March $17^{\text {th }}, 2011$.
}

\begin{abstract}
Recombinant plant-derived pharmaceuticals have been investigated for the last two decades and some products will soon be brought to market. Since veterinary pharmaceuticals seem to be the front-runners of plant-derived vaccines, we selected one model subunit vaccine, the structural capsid protein VP60 against rabbit haemorrhagic disease, and analyzed the expression of three different sequences representing the VP60 open reading frame in potato plants. The generation of antigenic VP60 molecules in the leaf and tuber tissue of potato was tremendously enhanced by replacing virus-derived sequences with plant-optimized codons. In order to identify potentially undesirable alterations in the composition of these genetically modified food components, we studied their nutrient composition and nutritional value in comparison to two parental conventional breeding varieties (Albatros and Desiree). The largest differences in nutrient composition were found between the two conventional breeds and between conventional Desiree and its near-isogenic genetically modified potato plant, indicating that genetic modification as well as conventional breeding can influence nutrient composition. Nevertheless, most parameters of nutritional value seemed to be more affected by conventional breeding than by genetic modification.
\end{abstract}

Keywords: Recombinant Plant-Derived Vaccines, VP60, RHDV, Animal Nutrition, Nutritional Assessment

\section{Introduction}

In recent years, predominantly transgenic plants of the so-called first generation, with input traits like insect resistance or herbicide tolerance, were generated, cultivated and analyzed [1]. Soon, plants of the second and third generation, with output traits like specific components of technical interest [2,3], modified nutritional values [4,5], or plant-based pharmaceuticals [6] are supposed to enter the market. Remarkably, after 20 years of research, recombinant pharmaceutical plants or plant cells are still not on the market [7]. This might either be due to the inadequate expression level or uptake of the pharmaceuticals, as well as to the high production costs, which are mainly caused by the application process and the extensive risk assessment. Nevertheless, some plantderived recombinant pharmaceuticals established for the treatment of human diseases and veterinary vaccines are now approaching commercialization [8].

Although research worldwide mainly focuses on human therapeutics [9], important improvements have been achieved in the sector of animal health products $[10,11]$. Since the application of transgenic plant products to humans is still under great discussion, we can speculate that veterinary pharmaceuticals, and especially vaccines, will be the front runners in the process of commercialisation. Therefore, we decided to concentrate on plant-derived animal immunogens. In a model study we generated antigen-producing potato tubers expressing the major capsid protein VP60 of the Rabbit haemorrhagic disease virus (RHDV) as an interesting veterinary vaccine candidate. VP60 was shown to induce a strong immune response and to protect rabbits against rabbit haemorrhagic disease (RHD) [12]. RHD, an acute and highly conta- 
gious disease in wild and domestic rabbits, was first reported by Liu et al. 1984 in the People's Republic of China, after which it spread throughout other parts of Asia, Europe, Africa and the Central and North American continent $[13,14]$. The characteristic pathological signs of RHD are liver damage and haemorrhages in the lung, trachea, liver, spleen, cardiac muscle, and occasionally in the kidneys [15]. Because of the lack of a cell culture system to propagate RHD virus (RHDV) in vitro, so far, all commercially available vaccines against RHDV are based on liver homogenates from RHDVinfected rabbits.

In recent years, VP60 has been successfully expressed in several heterologous systems such as Escherichia coli [16], Saccharomyces cerevisiae [17], baculovirus [18-20], poxvirus [21-23], and plants [24-26]. The oral applications of baculovirus-expressed VP60 [27] and potatoproduced VP60 [28] in rabbits gave positive results, a promising indication for the replacement of traditional RHD vaccine production in the near future.

However, such genetically modified (GM) plants or organisms have given rise to an increased concern about the safety of these products in the food chain [29]. "Unintended effects" were proposed to result from the genetic modification process. Although all results available to date reveal no significant differences in the safety and nutritional value of feedstuffs containing material derived from the so-called first generation of genetically modified plants [30], allergenic effects have been reported for soy beans expressing brazil-nut $2 \mathrm{~S}$ albumin [31] and for peas expressing $\alpha$-amylase inhibitor- 1 from the common bean [32]. Different nutritional composition has also been observed in GM plants as compared to near-isogenic parental control plants (Momma et al., 1999: increased protein content in GM rice; Hashimoto et al., 1999: augmented glycoalkaloid content in GM potatoes).

In order to ensure that no unintended changes in nutrient composition or nutritional value occurred in our GM potato, we compared it to its near-isogenic conventional potato counterpart and carried out a feeding experiment with rats. Taking into consideration that not only the transgene itself but also other factors like potato variety, location of transgene integration and somaclonal variation can affect nutrient composition and nutritional value and can have physiological impacts, two breeds of conventional potatoes plus three transgenic potato plants were tested.

\section{Materials and Methods}

\subsection{DNA Constructs and Construction of Plant Expression Vectors}

The coding sequence of $v p 60$ was designed according to the codon usage of Nicotiana tabacum and based on the VP60 sequence of the RHDV isolate "Eisenhüttenstadt" (accession number Y15440), 2/18 (R590 2/18). The motif GCTTCCTCC was inserted immediately after the VP60 start codon and the motif TCTGAAAAGGATGAACTT immediately in front of the stop codon. The synthesis was carried out using synthetic nucleotides in the LCR (ligase chain reaction). The natural and synthetic VP60 coding regions (Figure 1) were fused to the CaMV 35S promoter and 35S-terminator and integrated into the binary plasmid pGK (Keil, unpublished), leading

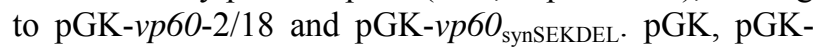
$v p 60-2 / 18$ and pGK-vp60 6 synSEKDEL were introduced into the Agrobacterium tumefaciens strain LBA4404.

Moreover, the synthetic vp60 sequence was fused to a synthetic sequence of the non-toxic subunit B of cholera toxin and integrated between the regulatory regions of GBSS promoter and t-nos terminator in the binary plasmid pPGB-1S [33] to obtain tuber-specific expression. The plasmids pPGB-1S and pP-ctbvp $60_{\text {synSEKDEL }}$ were introduced into the Agrobacterium tumefaciens strain LBA4404.

\subsection{Bacterial Strains and Plant Transformation}

Agrobacterium tumefaciens strain LBA4404, containing the binary plasmids pGK, pGK-vp60-2/18, pGK-vp60 synSEKDEL, $_{\text {, }}$ pPGB-1S or pP-ctBvp60 $0_{\text {synSEKDEL }}$ were propagated under selective pressure and used to infect potato plants using a transformation and regeneration protocol according to [34] with slight modifications. Potato leaves were wounded with razor blades and co-cultivated for three days with Agrobacteria. To induce callus material explants were cultivated for 10 days on MS medium supplemented with $5 \mathrm{mg} \mathrm{L}^{-1} \alpha$-naphthaleneacetic (NAA), 0.1 $\mathrm{mg} \mathrm{L}^{-1}$ 6-benzylaminopurine (BAP), $100 \mathrm{mg} \mathrm{L}^{-1}$ kanamycin and $250 \mathrm{mg} \mathrm{L}^{-1}$ cefotaxime. Explants were transferred to MS medium supplemented with $2 \mathrm{mg} \mathrm{L}^{-1}$ zeatinribose, $0.02 \mathrm{mg} \mathrm{L}^{-1} \alpha$-naphthaleneacetic (NAA), 0.002 gibberellic acid, $\left(\mathrm{GA}_{3}\right), 100 \mathrm{mg} \mathrm{L}^{-1}$ kanamycin and 250 $\mathrm{mg} \mathrm{L}^{-1}$ cefotaxime. The explants were transferred to fresh medium every two weeks. Shoots were transferred to hormone-free MS medium containing $100 \mathrm{mg} \mathrm{L}^{-1} \mathrm{kana}-$ mycin and $250 \mathrm{mg} \mathrm{L}^{-1}$ cefotaxime for root induction. pGK and pGKvp60 $0_{\text {SEKDEL }}$ were introduced into the cultivars Desiree and Albatros, while pPGB-1S and pP-ctbvp $60_{\text {SEKDEL }}$ were introduced into Albatros potatoes.

\subsection{Detection of vp60, ctb and npt II Genes in Transformed Plants}

Genomic DNA was isolated from young leaves of transformed potato plants using Qiagen DNeasy Plant Mini Kit, according to the manufacturer's instructions (Qiagen, Hilden, Germany). The presence of the genes was deter- 


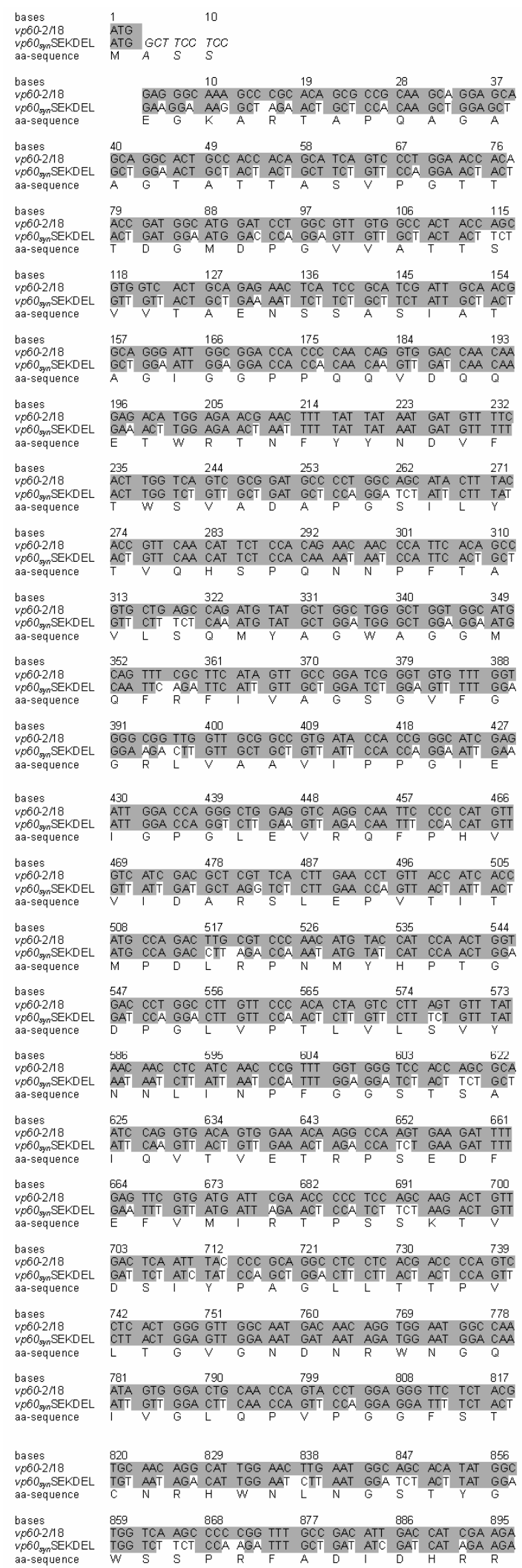

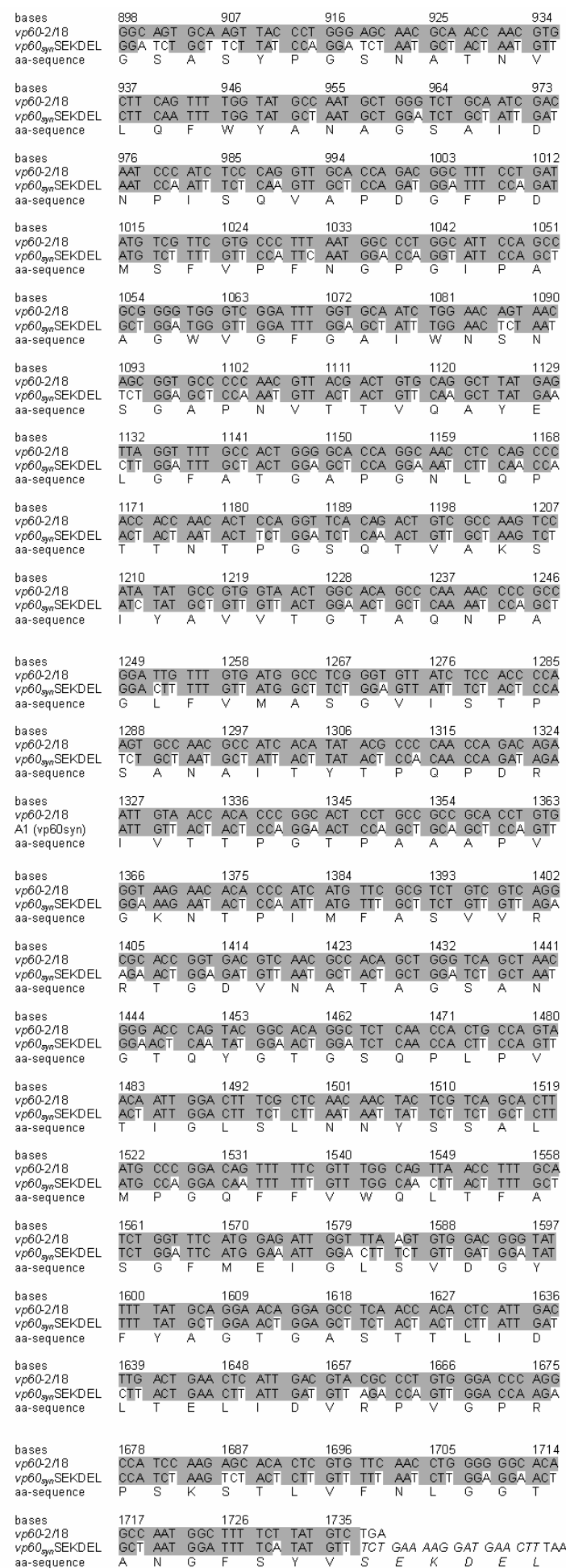

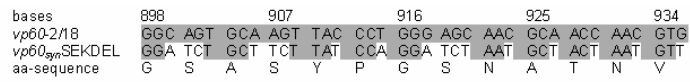
$\begin{array}{llllll}\text { bases } & 937 & 946 & 955 & 964 & 973 \\ \text { vp60-2118 } & \text { CTT CAG TTT TGG TAT GCC AAT GCT GGG TCT GCA ATC GAC } \\ \text { vp6005STEKDEL } & \text { CTT CAA TTT TGG TAT GCT AAT GCT GGA TCT GCT ATT GAT }\end{array}$

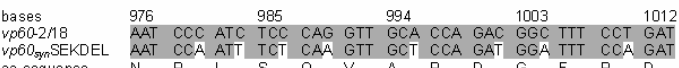
aa-sequence $N$ P 1 S $Q$ Q $\vee$ A

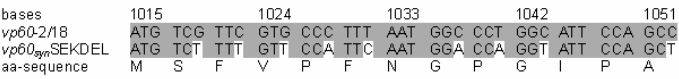

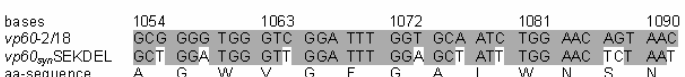

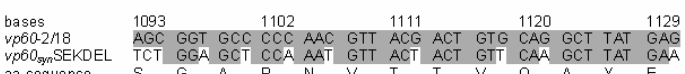

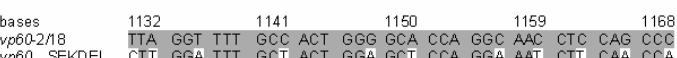

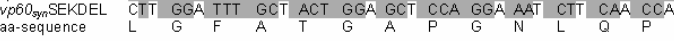

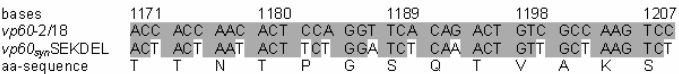

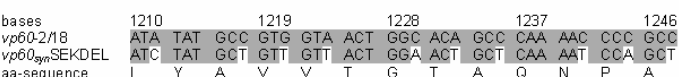

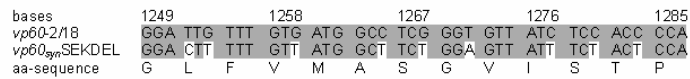

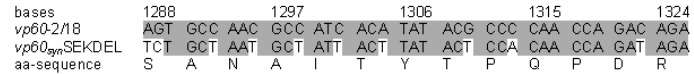

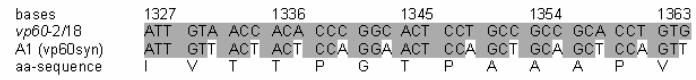

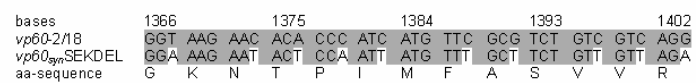

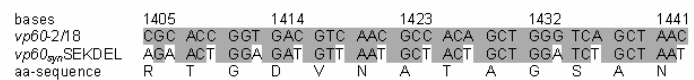

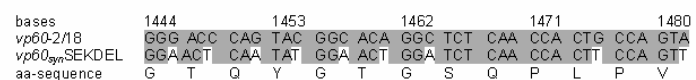

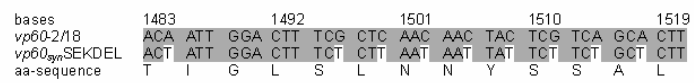

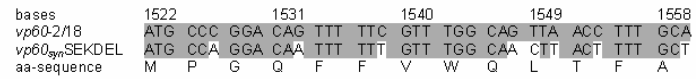

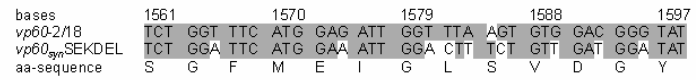

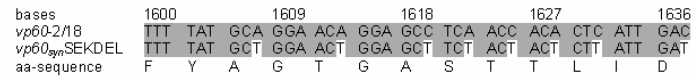

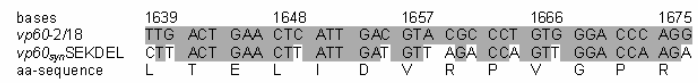

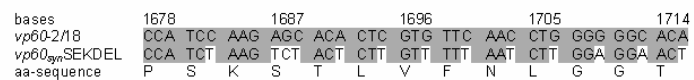

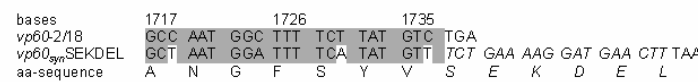

Figure 1. Sequence of the natural VP60 coding region (virus isolate R590-2/18) and the derived synthetic sequence (tobacco codon preference) with the corresponding amino acid sequence. 
mined by PCR analysis using primers VP60-2/18-fw and VP60-rv, VP60syn-fw and VP60syn-rv, 2npt-fw and 2nptrv, ctBfw_1 and ctBrv_1 (Table 1). Cycling conditions were as follows: $95^{\circ} \mathrm{C}$ for $5 \mathrm{~min}$, followed by 37 cycles of $95^{\circ} \mathrm{C}$ for $1 \mathrm{~min}, 54^{\circ} \mathrm{C}$ for $1 \mathrm{~min}$ and $72^{\circ} \mathrm{C}$ for $1 \mathrm{~min}$, and a final elongation at $72^{\circ} \mathrm{C}$ for $10 \mathrm{~min}$. The PCR products were analyzed on a $2 \%$ agarose gel.

\subsection{Analysis of RNA from Transformed Tomato Plants}

Total RNA from leaves and tubers of transformed potato plants was isolated according to the method of Logemann et al. (1987). $1 \mu \mathrm{g}$ of total RNA was used for DNase treatment, followed by a reverse transcription assay using the Qiagen Omniscript RT kit according to the manufacturer's instructions (Qiagen, Hilden, Germany). PCR was subsequently used, as described above, to identify the mRNA of the vp60, ctb and npt II genes. The RT-PCR products were analyzed on a $2 \%$ agarose gel.

\subsection{RHDV Enzyme-Linked-Immunosorbent Assay (ELISA) of Plant Material}

Plant material was ground in liquid nitrogen and the resulting powder was extracted three times with phosphate-buffered saline PBS ( $\mathrm{pH} 7.2)$ by mixing and subsequent centrifugation ( $5 \mathrm{~min}, 16,000 \mathrm{~g}$ ). The total soluble protein content of each extract was determined by a Bradford assay [35].

ELISA was performed as previously described [36]. Briefly, plates were coated with RHDV antiserum raised in guinea pigs. After the plant extract was added, a mix of three murine monoclonal antibodies against VP60 was used to detect recombinant VP60. Visualisation was performed using peroxidase-labelled anti-mouse IgG (Sigma) and o-phenylenediamine (Sigma) as the substrate. Between the incubation steps the plates were washed three times with PBST [PBS, $0.05 \%$ Tween20 (v/v)]. Finally, the plate was measured at $492 \mathrm{~nm}$ using an ELISA reader (Anthos Lucy2). To calculate the relative amount of VP60 in the plant material the following equation was used, Index $=\left(\mathrm{OD}_{\text {sample }}-\mathrm{OD}_{\text {neg }}\right) /\left(\mathrm{OD}_{\text {pos }}-\mathrm{OD}_{\text {neg }}\right) .100$

Table 1. Oligonucleotides used for detection of $v p 60, c t b$ and nptII sequences.

\begin{tabular}{cc}
\hline Primer & Sequence \\
\hline VP60-2/18-fw & 5'-AAGCAGGAGCAGCAGGCACT-3' \\
VP60-rv & 5'-TGTCACCTGGATTGCGCTGG-3' \\
VP60syn-fw & 5'-AGGCTAGAACTGCTCCACAA-3', \\
VP60syn-rv & 5'-CCATTAGCAGTTCCTCCAAG-3' \\
ctBfw_1 & 5'-TTCTTATACTGAATCTCTTGCTGGA-3' \\
ctBrv_1 & 5'-CGGATCCAAGCTTTTAAGAAA-3' \\
2npt-fw & 5'-TCCGGCCGCTTGGGTGGAGAG-3' \\
2npt-rv & 5'-CTGGCGCGAGCCCCTGATGCT-3'
\end{tabular}

ng VP60 produced by a Baculovirus system served as standard.

\subsection{CTB ELISA of Plant Material}

Isolation and determination of total soluble protein occurred as described above. Detection and quantification of CTB protein in crude leaf extracts, as well as in potato tuber material was done by coating plates with rabbit antiserum against CTB (Natutec) diluted 1:2,000 in carbonate buffer ( $50 \mathrm{mM} \mathrm{N} \mathrm{CO}_{3}, \mathrm{pH}$ ), incubation for $2 \mathrm{~h}$ and blocking with $1 \%$ BSA solution for $1 \mathrm{~h}$. Plant samples were incubated in duplicated samples for two hours on coated plates, followed by incubation with goat antiserum against CTB diluted 1:5000 in PBS. After incubation with the anti-goat IgG-horseradish peroxidase conjugate (Dianova) diluted 1:5000 in PBS, visualisation was performed with a peroxidase labelled anti-rabbit IgG (Sigma) o-phenylenediamine as a substrate (Sigma). All incubation steps were done at $37^{\circ} \mathrm{C}$ and the intervening washing steps were repeated three times with PBST. Finally, the plate was measured at $405 \mathrm{~nm}$ using an ELISA reader (Anthos Lucy2). All plant samples were analysed three times, and an analysis of variance was carried out using the statistical analysis program Excel (Microsoft () .

\subsection{NPTII ELISA of Plant Material}

Isolation and determination of total soluble protein occurred as described above. Detection and quantification of NPTII protein in crude leaf extracts, as well as potato tuber material was performed by means of NPTII ELISA (Biofords) [37].

\subsection{Preparation and Analysis of Transgenic Dry Tuber Material}

Tubers of the three transgenic potato plants, Desiree/ GKvp60 $0_{\text {SEKDEL }}$ 6, Albatros/pPGB-1S \#210 and Al-

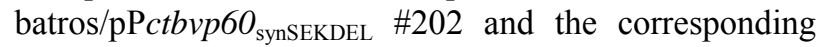
isogenic plants, Desiree and Albatros, were harvested and the raw material was lyophilised to concentrate the protein. The concentrations of VP60 and CTB were estimated using quantitative VP60- and CTB-ELISA. Additionally the content of neomycin-phosphotransferase II was determined.

\subsection{Animals, Diets and Experimental Design}

The feeding study was carried out with 40 young male Wistar rats (Charles River Laboratories, Germany), each weighing approximately $75 \mathrm{~g}$ at the beginning of the experiment. Animals were kept under standardized humidity $(60 \pm 5 \%)$ and temperature $\left(21.5 \pm 1{ }^{\circ} \mathrm{C}\right)$ with a $12 \mathrm{hr}$ light: $12 \mathrm{hr}$ dark regime in metabolism cages for 14 days. The animals were divided into five groups and were all 
fed a half-synthetic basic diet supplemented with casein ( $3 \%$ supplementation of methionine) as the sole protein source. Additionally, the animals received five different potatoes as fodder additives (D-niv, A-niv, A-NPTII, A-CTP: VP60, D-VP60, see Table 2; for detailed explanation see Figure 2), one potato construct per group. Potatoes were given in amounts so that $15 \%$ of dietary protein (based on $\mathrm{N}$ ) was supplied by the investigated potato plant.

All diets were iso-energetic and iso-nitrogenous, containing $150 \mathrm{mg}$ nitrogen per $10 \mathrm{~g}$ dry matter. Animals were fed for 14 days. Feed amount for each animal was adjusted according to the body weight (10 g dry matter per $100 \mathrm{~g}$ body weight) and was fed once a day. Free access to food and water was allowed. Body weight (BW) was recorded on days 1,8 and 14 of the feeding experiment, before feeding. From day 8 to day 14 the daily food intake was recorded, and the urine and feces were collected daily. $\mathrm{HCl}$ was added to urine and feces samples for storage at $4^{\circ} \mathrm{C}$ until analyses were done. At the end of the experiment the animals were sacrificed under inhalant isofluran (IsoFlo ${ }^{\circledR}$ ) anesthesia 12 hours after the last meal.

\subsection{Nutritional Value of Potato Tubers}

Amounts of principal nutrient components (dry matter (DM), crude ash (cA), crude fibre (cF), ether extract (EE), and nitrogen free extract (NfE)) in the five strains of potato plants were determined using the Weender standard procedure [38]. Crude protein (cP) was calculated from $\mathrm{N}$-content analyzed in the elementary analyzer LECO CNS 2000 applying the Dumas combustion technique $[39,40]$.

\subsection{Nitrogen Balance}

$\mathrm{N}$-content of all fecal samples as well as of pure potato lyophilisates (feed and uneaten feed) was determined as described above and was used for the evaluation of $\mathrm{N}$ balance. N-balance was further used for to calculate total tract apparent crude protein (TTACPD) and amino acids digestibility (TTACAAD), net protein utilization (NPU) and the protein efficiency ratio (PER) [41]. Endogenous and metabolic nitrogen were calculated using regression formulas based on rats' $\mathrm{BW}$ and $\mathrm{DM}$ intake, which were obtained in previous nitrogen-free experiments on rats that had been studied at the Research Institute for the Biology of Farm Animals [41].

\subsection{Amino Acid Composition}

The amount of total amino acids was determined in lyophilised potatoes and in feces by the Biochrom 20 Plus analyzer (Biochrom Ltd, Cambridge, UK) using automated ion exchange chromatography according to [42] and [43].

\subsection{Statistics}

Statistical analysis of parameter differences between animal groups and potato plants was done by means of one-factor ANOVA, followed by the HSD-Tukey Test $\left(\mathrm{SAS}^{\circledR}, 2002\right)$. A $p$-value $\leq 0.05$ was considered significant.

\section{Results}

\subsection{Enhancement of VP60 Content in Transgenic Potato Plants}

The expression of genes coding for pharmaceuticals is often too low to obtain sufficient amounts of protein in the plant cell, hence the content of transgene-encoded proteins should be increased in the plant cell. The amount of these proteins depends on the promoter used, the sequence of the coding region influencing RNA stability and translation, and the localisation of the protein in the plant cell that influences protein stability. One possibility for enhancing protein expression is the adoption of transgenes to the plants codon usage (e.g., Peng et al. 2006). Therefore we designed a coding region adapted to Nicotiana tabacum codon usage and compared its expression to the wild type gene (Figure 1). For a promoter, we chose the strong and constitutively expressed CaMV35S promoter which still is one of the strongest in potato leaves and quite strong in tubers, explaining its frequent application in potato (e.g., [44,45]. Additionally a GCTTCCTCC motif [46] was inserted immediately after the start codon ATG to stabilize the vp60 mRNA. To reduce protein degradation the sequence TCTGAAAAGGATGAACTT coding for the retention signal SEKDEL of the endoplasmatic reticulum [47] was linked 3' of the coding region. Three populations of transgenic potato plants expressing a) neomycin-phosph -otransferase II (NPTII), b) neomycin-phos- photransferase II and VP60 (natural sequence background) as well as c) neomycin-phosphotransferase II and VP60 $0_{\text {SEKDEL }}$ (synthetic sequence background) were generated via Agrobacterium-mediated transformation. The T-DNAs used for transforming plants are illustrated in Figure 2.

The cultivar Desiree was used to introduce pGK-vp602/18. Eight independent potato clones were established for further investigation. The cultivars Desiree and Albatros were used to introduce pGK and pGKvp60 $0_{\text {synSEKDEL }}$. Out of the many shoots regenerated on selective medium, 11 independent transgenic GKvp60 $0_{\text {synSEKDEL }}$ potato plants were established (seven for the variety Desiree and four for Albatros). The presence of the two different $v p 60$ coding regions was confirmed by PCR amplification of the genomic DNA (data not shown). Transcription was confirmed using RT-PCR. Transgenic plants constitu- 
tively expressing the neomycin-phosphotransferase II (GK) were used together with non-transgenic plants (near isogenic variety, niv) as controls for mRNA analysis to exclude false positive signals (Figure 3 ). In order to obtain VP60-producing potato material transgenic potato clones were grown in the greenhouse for tuberization. Afterwards, the tubers and leaves were analysed for the presence of VP60 using the VP60-ELISA. As shown in Figure 4, four transgenic Desiree/GK-vp60 $0_{\text {SEKDEL }}$ and four Albatros/GK-vp60 $0_{\text {SEKDEL }}$ plants showed high amounts of VP60 in leaves as well as in tuber material. Plants with the natural $v p 60-2 / 18$ coding sequence produced detectable VP60 (Figure 4). Compared to the viral sequence, the synthetic sequence resulted in a tremendous increase in VP60 production.

\subsection{Enhancement of the Antigenic Potential of Potatoes Producing VP60}

The biological activity of the antigen VP60 should be enhanced by the fusion of the vp60 sequence to a synthetic $c t B$ sequence (Figure 2). This effect has already been demonstrated for several different antigens [48-50]. Nevertheless, in some cases this fusion led to reduced expression levels or even to the failure of protein fusion complex production in plants $[51,52]$. Since the weight of CTB::VP60 is approximately $355 \mathrm{kDa}$ we worried about reduced levels of the fusion protein CTB::VP60 compared to VP60. In order to adjust the expression of the fusion protein to levels obtained for VP60 alone, the coding region was driven by the tuber specific GBSS promoter [53]. According to Visser et al. (1991), the GBSS promoter leads to higher $\beta$-glucorionidase activity in transgenic potato tubers compared to CaMV35S-gus fusions.

After Agrobacterium-mediated Albatros transformation, 17 independent transgenic Albatros/Pctbvp60 ${ }_{\text {synSEKDEL }}$ potato plants were obtained, and the presence of vp60 was confirmed by PCR amplification of the genomic DNA (data not shown). Again, total RNA from non-transgenic plants (niv), nptII plants (pPGBS121) and seven transgenic plants expressing tuber-specific ctbvp60 $0_{\text {synSEKDEL }}$ were assayed for the presence of the vp60-specific transcript using RT-PCR (data not shown). In VP60-ELISA tests, no transgenic Albatros/P-ctbvp60 synsEKDEL $_{\text {plants }}$ demonstrated detectable VP60 in leaf and tuber material. Hence, as assumed, the fusion of VP60 with CTB might have led to the drastic reduction of the amount of transgene-encoded protein in the cell, or the GBSS promoter used to enhance the expression was unable to drive VP60 expression. In order to verify the promoter effect, we fused GBSS with the VP60 coding region alone. No VP60 could be detected in the transgenic plants (data not shown).

\subsection{Selecting Transgenic Potato Plants \\ Producing VP60 for Feeding}

\section{Experiments}

The plant Desiree/GKvp60 SEKDEL $_{\text {\#6 (D-VP60) showed }}$ one of the highest VP60-Indexes (Figure 4). Around 4000 plants were propagated in vitro and grown in the greenhouse for tuberization. In addition, the Alba-

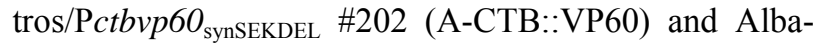
tros/PGB-1S \#210 (A-NPTII) were selected for feeding experiments. Even if no detectable amounts of VP60 could be demonstrated, mRNA specific to the $c t b$ and $v p 60_{\text {synSEKDEL }}$ coding regions could be detected in tuber

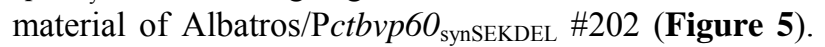
These plants were used for tuber production, with 700 plants per event. Harvested potato tubers were milled and then lyophilised. ELISA analyses of the powdered potato tuber material were used to verify VP60, CTB and NPTII content in the produced powdered potato material. Consequently, three transgenic plants containing different inserts (Table 2) and the corresponding near-isogenic variety, Desiree (D-niv) and Albatros (A-niv) were used for feeding experiments.

\subsection{Nutrient Composition and Nutritional Value of Transgenic and Conventionally Bred Potatoes}

Contents of the main nutrients of the two conventionally bred plants (A-niv, D-niv), their VP60/NPTII-expressing transgenic counterparts (A-CTB::VP60 and D-VP60) and a NPTII transgenic plant (A-NPTII) were comparatively analysed. In addition, the nutritional value of these potatoes was studied in a feeding experiment with rats. Based on a comparison of the conventional Albatros potato with all other varieties, the putative effects of conventional breeding including somatic cloning (A-niv vs. D-niv), the insertion and expression of the foreign $v p 60$ gene (A-niv vs. A-CTB::VP60 and D-niv vs. D-VP60) and the insertion of the nptII gene (A-niv vs. A-NPTII) were estimated. The differences between the both conventional varieties Desiree and Albatros were set to $100 \%$. Differences between all other plants are given in $\%$ of the difference between both conventional varieties Desiree and Albatros. Thus, relative differences of less than $100 \%$ (columns 2-4 in Tables 3 and 4) indicate that the differences between the transgenic plant and its corresponding conventionally bred variety were lower than the differences between the two varieties of conventionally bred plants.

\subsection{Nutrient Composition of Different Potato Varieties}

In Table 3 differences in the main nutrient components 
Table 2. Protein content of VP60, CTB and NPTII in freeze-dried potato tuber material, prepared for feeding experiments.

\begin{tabular}{|c|c|c|c|c|}
\hline Plant & Abbr. & VP60 $\mu \mathrm{g} / \mathrm{mg}$ TSP & CTB $\mu \mathrm{g} / \mathrm{mg}$ TSP & NPTII $\mu \mathrm{g} / \mathrm{mg}$ TSP \\
\hline Desiree, near isogenic variety & D-niv & 0 & 0 & 0 \\
\hline Albatros, near isogenic variety & A-niv & 0 & 0 & 0 \\
\hline Desiree/GKvp60 $0_{\text {synSEKDEL }} \# 6$ & D-VP60 & $0.21 \pm 0.140$ & 0 & $5.96 \pm 0.273$ \\
\hline Albatros/PGB1S \#210 & A-NPTII & 0 & 0 & $0.053 \pm 0.0004$ \\
\hline Albatros/Pctbvp $60_{\text {synSEKDEL }} \# 202$ & A-CTB::VP60 & $0.00042 \pm 0.000230$ & non detectable & $0.026 \pm 0.0050$ \\
\hline
\end{tabular}

Table 3. Effects of conventional breeding and genetic modification on nutrient composition in different potato lines and varieties.

\begin{tabular}{|c|c|c|c|c|c|c|}
\hline \multirow[b]{2}{*}{ Parameter } & \multicolumn{2}{|c|}{$\begin{array}{c}\text { Means of conventional } \\
\text { breeding variety }\end{array}$} & \multicolumn{4}{|c|}{ Comparison of lines (absolute differences) } \\
\hline & A-niv & D-niv & $\begin{array}{l}\text { D-niv } \\
\text { - A-niv }\end{array}$ & A-NPTII - A-niv & A-CTB::VP60 - A-niv & D-VP60 - D-niv \\
\hline $\begin{array}{r}\text { Dry matter } \\
(\mathrm{DM})[\%]\end{array}$ & 93.02 & 95.36 & $2.34(2.52 \%)$ & $0.11(0.12 \%)$ & $0.18(0.19 \%)$ & $0.82(0.86 \%)$ \\
\hline $\begin{array}{l}\text { Crude ash } \\
{[\% \text { DM }]}\end{array}$ & 3.74 & 4.20 & $0.46(12.30 \%)$ & $-0.01(-0.27 \%)$ & $-0.17(-4.55 \%)$ & $0.66(15.71 \%)$ \\
\hline Crude protein $[\% \mathrm{DM}]$ & 9.62 & 9.15 & $-0.47(-4.89 \%)$ & $-0.68(-7.07 \%)$ & $-0.02(-0.21 \%)$ & $6.23(68.09 \%)$ \\
\hline Crude fiber $[\% \mathrm{DM}]$ & 2.23 & 2.98 & $0.75(33.63 \%)$ & $0.27(12.11 \%)$ & $0.03(1.35 \%)$ & $6.22(208.72 \%)$ \\
\hline $\begin{array}{l}\text { Ether soluble } \\
\text { extract }[\% \mathrm{DM}]\end{array}$ & 0.28 & 0.41 & $0.13(46.43 \%)$ & $-0.02(-7.14 \%)$ & $-0.02(-7.14 \%)$ & $-0.05(-12.20 \%)$ \\
\hline $\begin{array}{l}\text { Nitrogen free } \\
\text { extract }[\% \mathrm{DM}]\end{array}$ & 85.63 & 83.15 & $-2.48(-2.9 \%)$ & $-0.30(-0.35 \%)$ & $0.70(0.82 \%)$ & $-13.50(-16.24 \%)$ \\
\hline $\begin{array}{c}\text { Total amino } \\
\text { acids }[\mathrm{g} / 16 \mathrm{~g} \mathrm{~N}]\end{array}$ & 84.57 & 70.33 & $-14.24(-16.84 \%)$ & $-7.26(-8.85 \%)$ & $-8.38(-9.91 \%)$ & $1.73(2.46 \%)$ \\
\hline
\end{tabular}

Table 4. Effects of conventional breeding and genetic modification in different potato lines and varieties on weight gain and parameters of nutritional value determined in rats.

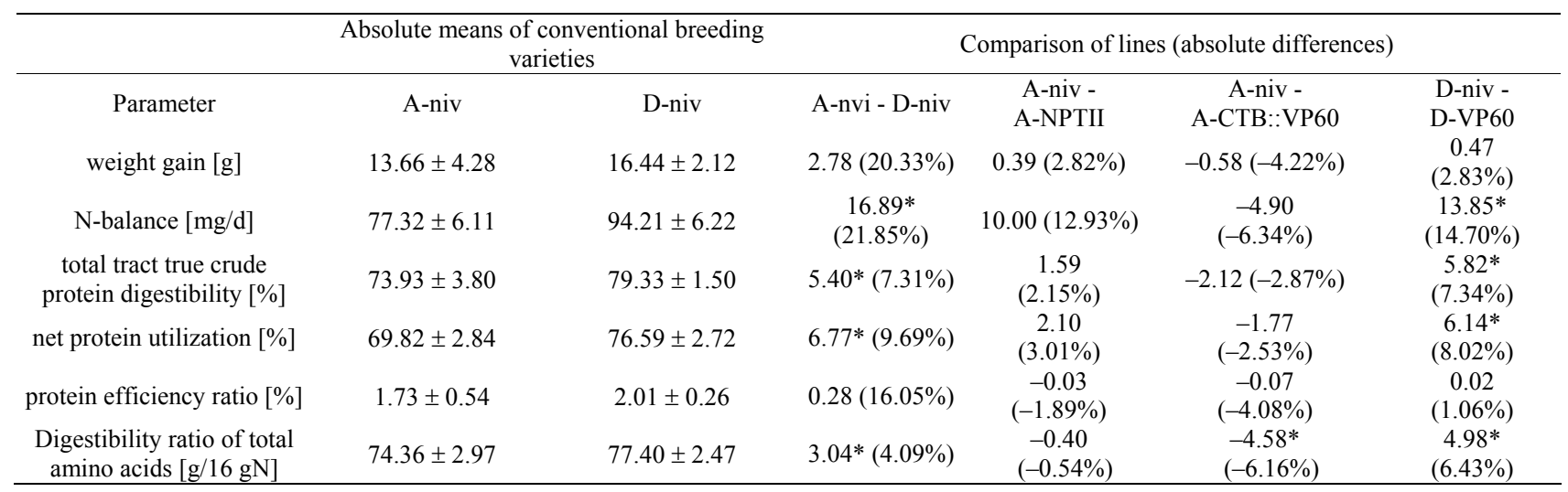

*Absolute differences between potato varieties are significant with $\mathrm{p} \leq 0.05$

between the compared potato varieties are shown. Considering both the number of traits exhibiting differences and the extent of differences, the strongest effects were observed between A-niv and D-niv as well as between D-niv and D-VP60. Absolute contents of crude fibre, ether extract, crude ash and total amino acids differed among both conventionally bred potatoes (A-niv and D-niv) between 3 to $46 \%$ (ether soluble extract). In relation to these results, the comparison of the A-niv potatoes with both transgenic potatoes (A-CTB::VP60 and A-NPTII) revealed fewer differences (i.e. $<100 \%$ ) in nearly all of the traits of nutrient composition (see Table 3 , columns 2 and 3). This result indicates that in the Al- batros potatoes investigated, neither the integration of foreign DNA nor the expression of $c t b v p 60_{\text {synSEKDEL }}$ and nptII caused changes in nutrient composition that were any greater than those observed between conventional breeding and somatic cloning. Only the difference in crude protein content between the NPTII-expressing Albatros and the conventional Albatros plant material was higher than that between Desiree and Albatros. In contrast, genetic modification of Desiree potatoes caused distinctive changes in nutrient composition. Differences in crude ash $(143.5 \%)$, crude protein $(-1325.5 \%)$, crude fibre $(829 \%)$ and nitrogen free extract content $(544.4 \%)$ considerably exceeded the differences $(100 \%)$ between 


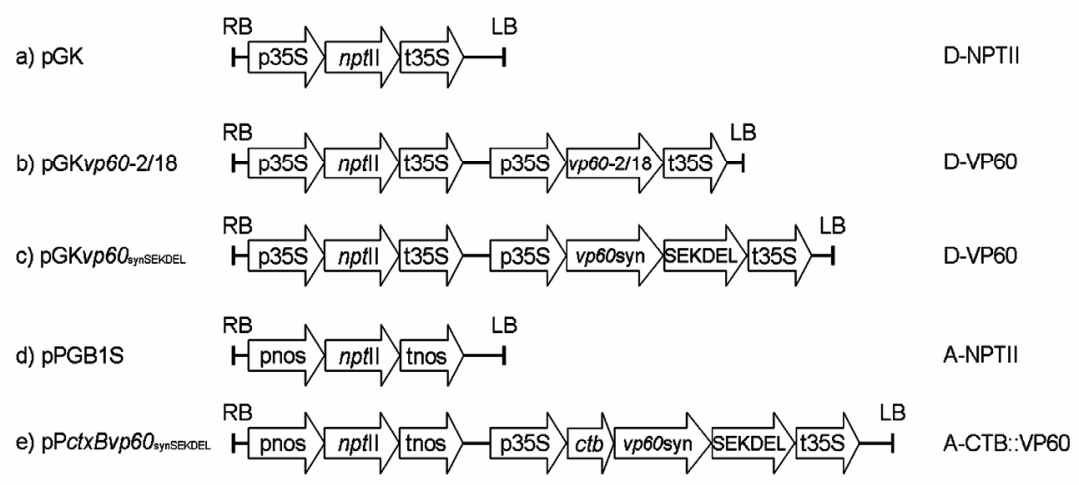

Figure 2. Schematic diagram of the constructs used for potato transformation to generate VP60-expressing plants. The constructs contain two different vp60 genes, one based on the natural sequence of the specific RHDV isolate "Eisenhüttenstadt“ (accession number Y15440), 2/18 (R590 2/18) and the second a synthetic vp60-sequence with tobacco codon usage as well as a synthetic $c t b$ sequence. The coding regions are under the control of the CaMV 35S promoter (p35S) and terminator (t35S). The marker gene neomycine phosphotransferase regulated by p35S and t35S is integrated in all constructs (b-e) and was used as an internal control (a).
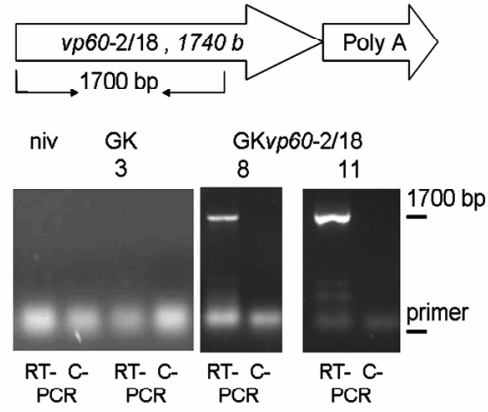

Desiree
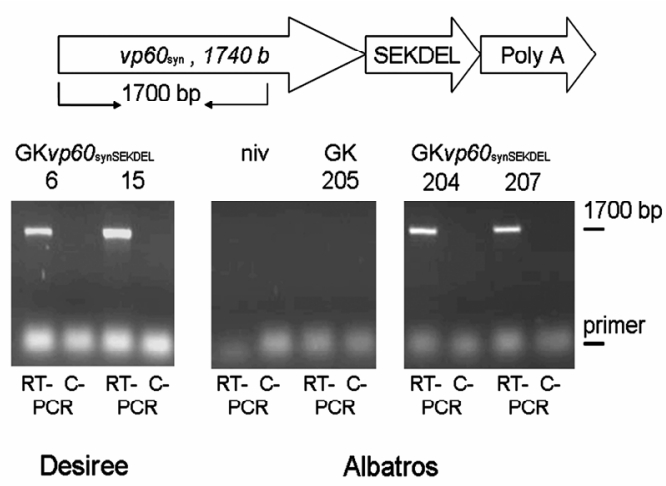

Desiree Albatros

Figure 3. Detection of transgene-specific transcripts by RT-PCR. RT-PCR was carried out using 1 $\mu$ of total RNA after DNase treatment, by using the Qiagen Omniscript RT kit. Oligonucleotides VP60 ${ }_{\text {syn }}$ fw and VP60 syn $_{\text {rv }}$ (Table 1) were used for amplification of $v p 60$-specific cDNA.

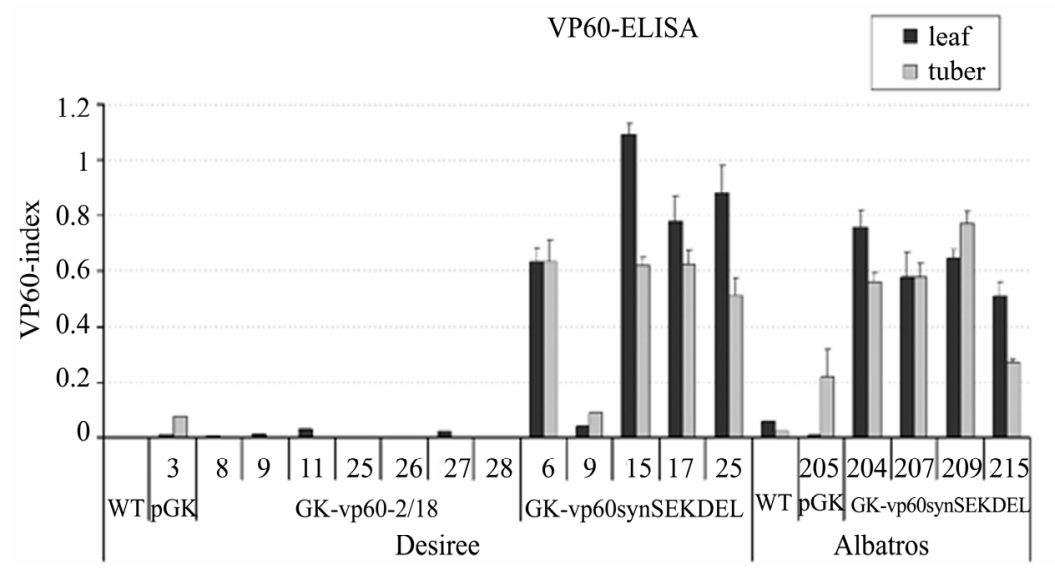

Figure 4. Detection of VP60 in transgenic potato plants Desiree and Albatros carrying the native and the synthetic vp60 coding region. The Index was generated by using the optical density at $405 \mathrm{~nm}$ of purified CTB, PBS, non-transformed plant material (near isogenic variety, niv) and plant material of the transgenic plants (OD transgenic line - OD wild type) / (OD purified CTB OD PBS). 

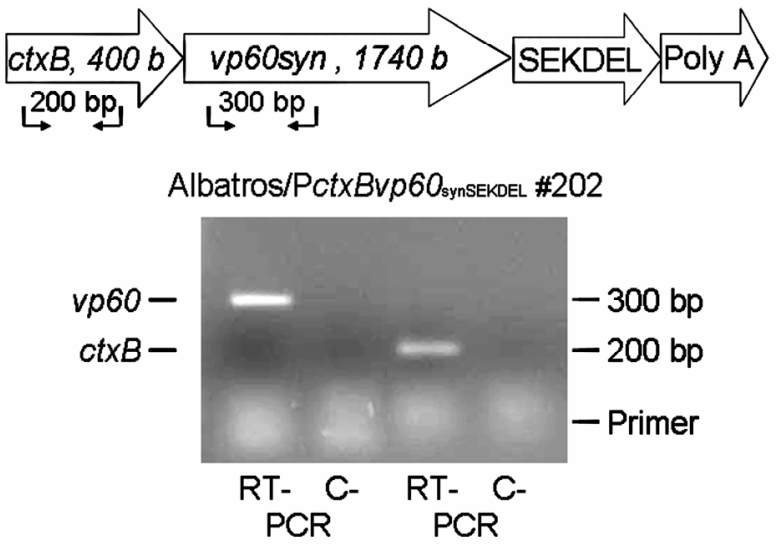

Figure 5. Detection of transgene-specific transcripts by RTPCR. RT-PCR was carried out using $1 \mu \mathrm{g}$ of total RNA after DNase treatment, by using the Qiagen Omniscript RT kit. Oligonucleotides VP60 syn $_{\mathrm{f}} \mathrm{w}$, VP60 syn $_{\mathrm{rv}}$, ctb-fwl and ctbrvl (Table 1) were used for the amplification of $v p 60$ - and $c t b$-specific cDNA.

the two conventional varieties (see Table 3, column 4). In particular, crude protein content seemed to be strongly affected.

\subsection{Nutritional Value of Different Transgenic Potatoes}

As expected from the different nutritional composition, both parental potato varieties Desiree and Albatros as well as VP60-expressing Desiree tubers exhibited significantly different nutritional values $(p<0.05)$ as revealed in a model feeding experiment with rats. When comparing D-niv with A-niv potatoes ingested by rats, a significantly lower nitrogen balance, total tract true crude protein digestibility, net protein utilization and digestibility ratio of total amino acids were observed in A-niv potatoes (see Table 4, column 1). Nevertheless, the weight gain of rats that ingested both potatoes did not differ significantly.

In comparison with the A-niv potato, the transgenic potato which expressed the VP60-antigen (A-CTB::VP60) and the NPTII-expressing transgenic potato (A-NPTII) did not exhibit significant differences in almost all parameters of nutritional value when fed to rats. Only the digestibility ratio of total amino acids of A-CTB::VP60 potatoes was significantly reduced (A-niv: $74.4 \mathrm{~g} / 16 \mathrm{~g} \mathrm{~N}$; A-CTB::VP60: $69.9 \mathrm{~g} / 16 \mathrm{~g} \mathrm{~N}$ ). Correspondingly, the extent of differences between the A-niv and the corresponding transgenic potatoes was smaller $(<100 \%)$ in relation to the variance between both niv-potatoes (see Table 4, columns 2 and 3). Similar results were observed for Desiree potatoes. Changes in most nutritional parameters between conventional Desiree and transgenic Desiree potatoes were smaller or equal in relation to the differences between the two parental potatoes (see Table 4, column 4), although compositional analysis had revealed distinctive variation.

\section{Discussion}

Codon adaptation of viral-derived vp60 open reading frame was essential to detect structural capsid protein VP60 in leaves and tubers of transgenic potato plants. In contrast to previously reported data [24,25], expression of virus-derived sequences in the potato variety Desiree was close to detection limit of VP60-ELISA and not sufficient for further analysis of nutritional parameters. Castanon and coworkers demonstrated a maximal expression of $0.3 \%$ TSP in leaves of transgenic Desiree plants by using a vp60 open reading frame from the Spanish isolate AST/89 [16] under the control of the 35S promoter [24]. This is higher then the detected level in the powdered tuber material (Table 2). The published Spanish isolate AST/89 [16] and RHDV-isolate "Eisenhüttenstadt" used in our work differ only in around $5 \%$ of the vp60 open reading frame. Moreover, the nos-terminator was used [24] instead of the 35S terminator applied in our expression analysis. Apparently, these small differences cause this tremendous difference in the expression of VP60 in potato. However, by using the synthetic vp60 sequence with codon adaptation to tobacco and the regulatory motif described by Sawant and coworkers [54], we demonstrated a tremendous enhancement of antigenic VP60 molecules in the leaves of transgenic Desiree plants. We assume this higher amount of accumulated viral proteins is due to the better availability of necessary t-RNAs [55] which compensate for the plant's uncommonly high frequency of specific amino acids like valine, alanine, glycine and proline in the amino acid chain of VP60.

In contrast to codon adaptation, the selected tuber-specific GBSS promoter did not increase the expression of VP60 in potato tubers, a result which also differs from that reported for the reporter protein GUS by others [56;57]. We assume that low expression can be caused by the negative effect of CTB::VP60 during first plant regeneration steps. This idea was confirmed by very low regeneration rates- $16 \%, 38 \%$ and $48 \%$ - obtained in three independent transformations [58]. In concordance, nearly the same reduction in regeneration rates- $20 \%$, $43 \%$ and $60 \%$ - was demonstrated for the expression of VP60 under the control of the GBSS promoter [58]. Strong induction of transgenes harbouring the GBSS promoter by sucrose during first stages of plant regeneration seems to have a higher negative influence compared with constitutive induction by $35 \mathrm{~S}$ promoter. On the 
other hand, different sequences in both untranslated regions (5' and 3' UTR) of the gene, due to cloning procedure, can cause high variation in expression. As shown in many studies, changes in these regulatory regions can dramatically affect the expression of coding regions [59;60]. The genetic fusion of the $c t b$ and vp60 open reading frames under the control of the GBSS promoter did not lead to an accumulation of immunogenic CTB::VP60 molecules in potato plants. However, in tobacco and pea plants, expressed CTB::VP60 could demonstrate a tremendous enhancement of immunogenicity as compared to VP60 [61]. Because of the fact that only a few nanograms of VP60 in the complex of the fusion antigen CTB::VP60 are able to induce immunogenicity in rabbits, we integrated this construct into Albatros, expressed under the GBSS control in compositional analysis and feeding trials.

The objective of compositional analysis and the feeding experiments with rats was to investigate the effect of the integration of different transgenes, nptII, nptII + vp60 and $n p t I I+c t b v p 60_{\text {synSEKDEL }}$, on the nutrient composition of the potato tuber, on its nutritional value and on weight gain in rats. Taking into account that conventional breeding can change the nutritional value distinctively and is never trusted to be safe, we related all our data to the measured difference between two conventional potatoes varieties (Albatros and Desiree). These changes were set as $100 \%$.

Both conventional varieties (A-niv and D-niv) varied in nutrient composition $(\mathrm{DM}, \mathrm{cA}, \mathrm{cP}, \mathrm{cF}, \mathrm{EE}, \mathrm{NfE}$, total amino acids) and in nutritional value (N-balance, TTtPD, NPU, PER, digestibility of amino acids), indicating that normal breeding procedures modify nutrient composition and nutritional value of the potato varieties studied in this experiment. Moreover the weight gain of rats was slightly affected. These effects are probably due to intentional breeding for certain traits but can also be caused unintentionally by somaclonal variation if in vitro plant regeneration is used [62]. Analogous results were observed when comparing the nutrient composition and nutritional value of transgenic Albatros potatoes expressing either the nptII gene (A-NPTII) or the $c t b$ $v p 60_{\text {synSEKDEL }}+n p t I I$ genes with its near-isogenic parental wildtype potato (A-niv), but these differences were less distinct. Distinctive changes were found when comparing D-niv with its VP60-expressing counterpart (D-VP60). It was especially notable that crude protein content was considerably elevated in the transgenic tubers. Nevertheless, the nutritional parameters were hardly affected by these strong differences. They were within the variance range of conventional breeding effects (comparison of A-niv vs. D-niv) and in most parameters these effects seemed to be even stronger than those resulting from genetic modification. The reason for these observed occurrences are difficult to identify. It is known that DNA integration is random and gene disruption, sequence changes or the production of new proteins can occur as a consequence of the recombination event [63]. Whether the mentioned results are due to such interactions or due to somaclonal variation - a reprogramming during plant regeneration [64] — cannot be judged by this study. Nevertheless, it becomes clear that any process involved in genetic modification may possibly lead to compositional and nutritional changes. However, it can be also concluded that conventional breeding methods can do so as well. In our opinion, the reported differences in nutrient composition and nutritional value of the genetically modified potatoes are not drastic in reference to Albatros potatoes. Many differences did not even exceed the variation caused by normal conventional breeding methods. These results are in agreement with findings of Catchpole et al. [65], who observed that metabolic changes caused through conventional breeding were at least of a comparable magnitude to those that resulted as an unintended effect of genetic engineering techniques. Genetic modification of Desiree potatoes led to stronger differences in nutrient composition. Nevertheless, parameters of nutritional value were hardly affected and the weight gain of rats that ingested the potatoes was comparable to differences between the conventional varieties. Taking into account that these potatoes are supposed to be applied as food additives and not as main nutrient source, we conclude that the observed changes in the investigated potatoes do not point out to any harmful effect on the animals in short time application. The results of [66] (2007), who demonstrated that blood and serum parameters of rats that ingested the same transgenic potatoes did not show significant differences compared to rats fed the corresponding conventional potato varieties, support our conclusion. Regardless, it becomes evident that changes in nutrient composition and nutritional value may occur and that studies investigating these side effects are essential when introducing genetically modified plants or even new varieties into the food chain.

\section{Acknowledgements}

This work was supported by Federal Ministry for Education and Research (BMBF), project Nr. 0312744. The authors are solely responsible for the presented results, and they do not represent any interest of the BMBF.

\section{REFERENCE}

[1] K. Yonekura-Sakakibara and K. Saito, "Review: Genetically Modified Plants for the Promotion of Human 
Health," Biotechnology Letters, Vol. 28, 2006, pp. 19831991. doi:10.1007/s10529-006-9194-4

[2] M. Huhns, K. Neumann, T. Hausmann, K. Ziegler, F. Klemke, U. Kahmann, D. Staiger, W. Lockau, E. K. Pistorius and I. Broer, "Plastid Targeting Strategies for Cyanophycin Synthetase to Achieve High-Level Polymer Accumulation in Nicotiana Tabacum," Plant Biotechnol Journal, Vol. 6, No. 4, 2008, pp. 321-336. doi:10.1111/j.1467-7652.2007.00320.x

[3] K. Neumann, D. P. Stephan, K. Ziegler, M. Huhns, I. Broer, W. Lockau and E. K. Pistorius, "Production of Cyanophycin, a Suitable Source for the Biodegradable Polymer Polyaspartate, in Transgenic Plants," Plant Biotechnology Journal, Vol. 3, No. 2, 2005, pp. 249-258. doi:10.1111/j.1467-7652.2005.00122.x

[4] J. A. Paine, C. A. Shipton, S. Chaggar, R. M. Howells, M. J. Kennedy, G. Vernon, S. Y. Wright, E. Hinchliffe, J. L. Adams, A. L. Silverstone and R. Drake, "Improving the Nutritional Value of Golden Rice through Increased Pro-Vitamin A Content," Nature Biotechnology, Vol. 23, No. 4, 2005, pp. 482-488. doi:10.1038/nbt1082

[5] S. Storozhenko, S. Ravanel, G. F. Zhang, F. Rebeille, W. Lambert and D. Van Der Straeten, "Folate Enhancement in Staple Crops by Metabolic Engineering," Trends in Food Science \& Technology, Vol. 16, No. 6-7, 2005, pp. 271-281. doi:10.1016/j.tifs.2005.03.007

[6] A. V. Karasev, S. Foulke, C. Wellens, A. Rich, K. J. Shon, I. Zwierzynski, D. Hone, H. Koprowski and M. Reitz, "Plant Based HIV-1 Vaccine Candidate: Tat Protein Produced in Spinach," Vaccine, Vol. 23, 2005, pp. 18751880. doi:10.1016/j.vaccine.2004.11.021

[7] J. K. C. Ma, P. M. W. Drake, D. Chargelegue, P. Obregon and A. Prada, "Antibody Processing and Engineering in Plants, and New Strategies for Vaccine Production," Vaccine, Vol. 23, No. 15, 2005, pp. 1814-1818.

[8] J. K .C. Ma, E. Barros, R. Bock, P. Christou, P. J. Dale, P. J. Dix, R. Fischer, J. Irwin, R. Mahoney, M. Pezzotti, S. Schillberg, P. Sparrow, E. Stoger and R. M.Twyman, "Molecular Farming for New Drugs and VaccinesCurrent Perspectives on the Production of Pharmaceuticals in Transgenic Plants," Embo Reports, Vol. 6, 2005, pp. 593-599. doi:10.1038/sj.embor.7400470

[9] S. J. Streatfield and J. A. Howard, "Plant-Based Vaccines," International Journal for Parasitology, Vol. 33, No. 5-6, 2003, pp. 479-493.

[10] D. M. Floss, D. Falkenburg and U. Conrad, "Production of Vaccines and Therapeutic Antibodies for Veterinary Applications in Transgenic Plants: An Overview," Transgenic Research, Vol. 16, No. 3, 2007, pp. 315-332.

[11] M. J. D. Santos and A. Wigdorovitz, "Transgenic Plants for the Production of Veterinary Vaccines," Immunology and Cell Biology, Vol. 83, No. 3, 2005, pp. 229-238.

[12] J. L. Martinez-Torrecuadrada, E. Cortes, C. Vela, J. P. M. Langeveld, R. H. Meloen, K. Dalsgaard, W. D. O. Hamilton and J. I. Casal, "Antigenic Structure of the Capsid Protein of Rabbit Haemorrhagic Disease Virus," Journal of General Virology, Vol. 79, 1998, pp. 1901-1909.
[13] B. D. Cooke. "Rabbit Haemorrhagic Disease: Field Epidemiology and the Management of Wild Rabbit Populations," Rev Sci Tech, Vol. 21, No. 2, 2002, pp. 347-358.

[14] H.-B. Huang, "Vaccination against and Immune Response to Viral Haemorrhagic Disease of Rabbits: A Review of Research in the People's Republic of China," Rev sci tech Off int Epiz, Vol. 10, 1991, pp. 481-498.

[15] C. Alonso, J. M. Oviedo, J. M. Martin-Alonso, E. Diaz, J. A. Boga and F. Parra, "Programmed Cell Death in the Pathogenesis of Rabbit Hemorrhagic Disease," Archives of Virology, Vol. 143, No. 2, 1998, pp. 321-332. doi:10.1007/s007050050289

[16] J. A. Boga, R. Casais, M. S. Marin, J. M. Martinalonso, R. S. Carmenes, M. Prieto and F. Parra, "Molecular-Cloning, Sequencing and Expression in Escherichia-Coli of the Capsid Protein Gene from Rabbit Hemorrhagic-Disease Virus (Spanish Isolate Ast/89)," Journal of General Virology, Vol. 75, 1994, pp. 2409-2413. doi:10.1099/0022-1317-75-9-2409

[17] J. A. Boga, J. M. M. Alonso, R. Casais and F. Parra, "A Single Dose Immunization with Rabbit Haemorrhagic Disease Virus Major Capsid Protein Produced in Saccharomyces Cerevisiae Induces Protection," Journal of General Virology, Vol. 78, No. 9, 1997, pp. 2315-2318.

[18] S. Laurent, J. F. Vautherot, M. F. Madelaine, G. G. Le and D. Rasschaert, "Recombinant Rabbit Hemorrhagic Disease Virus Capsid Protein Expressed in Baculovirus Self-Assembles into Viruslike Particles and Induces Protection," Journal of Virology, Vol. 68, 1994, pp. 67946798.

[19] H. S. Nagesha, L. F. Wang, A. D. Hyatt, C. J. Morrissy, C. Lenghaus and H. A. Westbury, "Self-Assembly, Antigenicity, and Immunogenicity of the Rabbit Hemorrhagic-Disease Virus (Czechoslovakian Strain V-351) Capsid Protein Expressed in Baculovirus," Archives of Virology, Vol. 140, 1995, pp. 1095-1108.

[20] M. Sibilia, M. B. Boniotti, P. Angoscini, L. Capucci and C. Rossi, "2 Independent Pathways of Expression Lead to Self-Assembly of the Rabbit Hemorrhagic-Disease Virus Capsid Protein," Journal of Virology, Vol. 69, 1995, pp. 5812-5815.

[21] S. Bertagnoli, J. Gelfi, F. Petit, J. F. Vautherot, D. Rasschaert, S. Laurent, G. LeGall, E. Boilletot, J. Chantal and C. BoucrautBaralon, "Protection of Rabbits against Rabbit Viral Haemorrhagic Disease with a Vaccinia-RHDV Recombinant Virus," Vaccine, Vol. 14, No. 6, 1996, pp. 506-510. doi:10.1016/0264-410X(95)00232-P

[22] S. Bertagnoli, J. Gelfi, G. LeGall, E. Boilletot, J. F. Vautherot, D. Rasschaert, S. Laurent, F. Petit, C. BoucrautBaralon and A. Milon, "Protection against Myxomatosis and Rabbit Viral Hemorrhagic Disease with Recombinant Myxoma Viruses Expressing Rabbit Hemorrhagic Disease Virus Capsid Protein," Journal of Virology, Vol. 70, No. 8, 1996, pp. 5061-5066.

[23] L. Fischer, F. X. Legros, P. W. Mason and E. Paoletti, “A Recombinant Canarypox Virus Protects Rabbits against a Lethal Rabbit Hemorrhagic Disease Virus (RHDV) Challenge," Vaccine, Vol. 15, No. 1, 1997, pp. 90-96. 
[24] S. Castanon, M. S. Marin, J. M. Martin-Alonso, J. A. Boga, R. Casais, J. M. Humara, R. J. Ordas and F. Parra, "Immunization with Potato Plants Expressing VP60 Protein Protects against Rabbit Hemorrhagic Disease Virus," Journal of Virology, Vol. 73, No. 5, 1999, pp. 4452-4455.

[25] S. Castanon, J. M. Martin-Alonso, M. S. Marin, J. A. Boga, P. Alonso, F. Parra and R. J. Ordas, "The Effect of the Promoter on Expression of VP60 Gene from Rabbit Hemorrhagic Disease Virus in Potato Plants," Plant Science, Vol. 162, No. 1, 2002, pp. 87-95. doi:10.1016/S0168-9452(01)00535-0

[26] M. R. Fernandez-Fernandez, M. Mourino, J. Rivera, F. Rodriguez, J. Plana-Duran and J. A. Garcia, "Protection of Rabbits against Rabbit Hemorrhagic Disease Virus by Immunization with the VP60 Protein Expressed in Plants with a Potyvirus-Based Vector," Virology, Vol. 280, No. 2, 2001, pp. 283-291.

[27] J. PlanaDuran, M. Bastons, M. J. Rodriguez, I. Climent, E. Cortes, C.Vela and I. Casal, "Oral Immunization of Rabbits with VP60 Particles Confers Protection against Rabbit Hemorrhagic Disease," Archives of Virology, Vol. 141, 1996, pp. 1423-1436.

[28] J. M. Martin-Alonso, S. Castanon, P. Alonso, F. Parra and R. Ordas, "Oral Immunization Using Tuber Extracts from Transgenic Potato Plants Expressing Rabbit Hemorrhagic Disease Virus Capsid Protein," Transgenic Research, Vol. 12, 2003, pp. 127-130. doi:10.1023/A:1022112717331

[29] ILSI, "Nutritional and Safety Assessments of Foods and Feeds Nutritionally Improved through Biotechnolgy," Comprehensive Reviews in Food Science and Food Safety, Vol. 3, 2004, pp. 38-104.

[30] G. Flachowsky, A. Chesson, K. Aulrich. "Animal Nutrition with Feeds from Genetically Modified Plants," Archives of Animal Nutrition, Vol. 59, 2005, pp. 1-40.

[31] J. A. Nordlee, S. L. Taylor, J. A. Townsend, L. A. Thomas and R. K. Bush, "Identification of a Brazil-Nut Allergen in Transgenic Soybeans," New England Journal of Medicine, Vol. 334, No. 11, 1996, pp. 688-692. doi:10.1056/NEJM199603143341103

[32] V. E. Prescott, P. M. Campbell, A. Moore, J. Mattes, M. E. Rothenberg, P. S. Foster, T. J. V. Higgins and S. P. Hogan, "Transgenic Expression of Bean Alpha-Amylase Inhibitor in Peas Results in Altered Structure and Immunogenicity," Journal of Agricultural and Food Chemistry, Vol. 53, 2005, pp. 9023-9030.

[33] A. G. Kuipers, W. J. Soppe, E. Jacobsen and R. G. Visser, "Factors Affecting the Inhibition by Antisense RNA of Granule-Bound Starch Synthase Gene Expression in Potato," Molecular \& General Genetics, Vol. 246, 1995, pp. 745-755. doi:10.1007/BF00290722

[34] R. Horsch, J. Fry, N. L. Hoffmann, D. Eichholtz, S. G. Rogers and R. T. Fraley, "A Simple and General Method for Transferring Genes into Plants," Science, Vol. 227, No. 4691, 1985, pp. 1229-1231.

[35] M. M. Bradford. "Rapid and Sensitive Method for Quantitation of Microgram Quantities of Protein Utilizing
Principle of Protein-Dye Binding," Analytical Biochemistry, Vol. 72, 1976, pp. 248-254.

[36] H. Schirrmeier, I. Reimann, B. Kollner and H. Granzow, "Pathogenic, Antigenic and Molecular Properties of Rabbit Haemorrhagic Disease Virus (RHDV) Isolated from Vaccinated Rabbits: Detection and Characterization of Antigenic Variants," Archives of Virology, Vol. 144, 1999, pp. 719-735. doi:10.1007/s007050050538

[37] I. S. Curtis, J. B. Power and M. R. Davey, "NPTII Assays for Measuring Gene Expression and Enzyme Activity in Transgenic Plants," Methods in Molecular Biology, Vol. 49, 1995, pp. 149-159.

[38] C. Naumann and R. Bassler, VDLUFA-Verlag, Darmstadt, 1993.

[39] W. W. Hauck, "A Review of Goodness of Fit Statistics for Use in the Development of Logistic Regression Models," American Journal of Epidemiology, Vol. 116, 1982, p. 732 .

[40] W. Kirsten, "Organic Elemental Analysis: Ultramicro, Micro and Trace Methods," Academic Press/Harcourt Brace Jovanovich, New York, 1983.

[41] P. Janczyk, "Evaluation of Nutritional Value and Activity of Green Microalgae Chlorella Vulgaris in Rats and Mice," Mensch und Buch Verlag, Berlin, 2005.

[42] F. Kreienbring and J. Wuensche, "Bericht über die Stickstoff- und Aminosäurenbestimmungs-Enquete 1971772 im Themekreis und über weitere methodische Arbeiten.," Akad Landwirtsch-Wiss DDR, Vol. 124, 1974, p. 34.

[43] F. Kreienbring. "Weiter Ergebnisse zur vergleichenden Bestimmung von Aminosäuren.," Nahrung, Vol. 31, 1987, pp. 855-862. doi:10.1002/food.19870310903

[44] Y. H. Joung, J. W. Youm, J. H. Jeon, B. C. Lee, C. J. Ryu, H. J. Hong, H. C. Kim, H. Joung and H. S. Kim, "Expression of the Hepatitis B Surface S And Pres2 Antigens in Tubers of Solanum Tuberosum," Plant Cell Reports, Vol. 22, 2004, pp. 925-930.

[45] M. Hajirezaei, I. Eickmeier, V. Mittendorf, U. Sonnewald, L. Willmitzer, A. R. Fernie, "Expression of an Escherichia Coli Phosphoglucomutase in Potato (Solanum Tuberosum L.) Results in Minor Changes in Tuber Metabolism and a Considerable Delay in Tuber Sprouting," Planta, Vol. 221, No. 6, 2005, pp. 915-927.

[46] S. V. Sawant, K. Kiran, P. K. Singh and R. Tuli, "Sequence Architecture Downstream of the Initiator Codon Enhances Gene Expression and Protein Stability in Plants," Plant Physiology, Vol. 126, 2001, pp. 16301636. doi:10.1104/pp.126.4.1630

[47] J. Roosien, F. A. van Engelen, G. A. de Jong, A. W. Borst-Vrenssen, J. F. Zilverentant, D. Bosch, W. J. Stiekema, F. J. Gommers, A. Schots and J. Bakker, "The C-Terminal KDEL Sequence Increases the Expression Level of a Single-Chain Antibody Designed to be Targeted to Both the Cytosol and the Secretory Pathway in Transgenic Tobacco," Plant Molecular Biology, Vol. 30, 1996, pp. 781-793. 
[48] T. Lagergard, M. Lindblad and J. Holmgren, "Local and Systemic Antibody Responses to Dextran-Cholera Toxin B Subunit Conjugates," Infection and Immunity, Vol. 63, No. 5, 1995, pp. 2021-2025.

[49] G. Hajishengallis, S. K. Hollingshead, T. Koga and M. W. Russell, "Mucosal Immunization with a Bacterial Protein Antigen Genetically Coupled to Cholera Toxin A2/B Subunits," Journal of Immunology, Vol. 154, 1995, pp. 4322-4332.

[50] J. Yu and W. H. R. Langridge, "A Plant-Based Multicomponent Vaccine Protects Mice from Enteric Diseases," Nature Biotechnology, Vol. 19, 2001, pp. 548552. doi: $10.1038 / 89297$

[51] N. W. Choi, M. K. Estes and W. H. R. Langridge, "Synthesis and Assembly of a Cholera Toxin B Subunit-Rotavirus VP7 Fusion Protein in Transgenic Potato," Molecular Biotechnology, Vol. 31, 2005, pp. 193-202. doi:10.1385/MB:31:3:193

[52] T. Harakuni, H. Sugawa, A. Komesu, M. Tadano and T. Arakawa, "Heteropentameric Cholera Toxin B Subunit Chimeric Molecules Genetically Fused to a Vaccine Antigen Induce Systemic and Mucosal Immune Responses: A Potential New Strategy to Target Recombinant Vaccine Antigens to Mucosal Immune Systems," Infection and Immunity, Vol. 73, 2005, pp. 5654-5665.

[53] F. R. Vanderleij, R. G. F. Visser, A. S. Ponstein, E. Jacobsen and W. J. Feenstra, "Sequence of the Structural Gene for Granule-Bound Starch Synthase of Potato (Solanum-Tuberosum L) and Evidence for a Single Point Deletion in the AMF Allele," Molecular \& General Genetics, Vol. 228, 1991, pp. 240-248.

[54] S. V. Sawant, K. Kiran, P. K. Singh and R. Tuli, "Sequence Architecture Downstream of the Initiator Codon Enhances Gene Expression and Protein Stability in Plants," Plant Physiology, Vol. 126, 2001, pp. 16301636. doi:10.1104/pp.126.4.1630

[55] C. Gustafsson, S. Govindarajan and J. Minshull, "Codon bias and Heterologous Protein Expression," Trends in Biotechnology, Vol. 22, 2004, pp. 346-353.

[56] D. G. Song, G. F. Sun, H. Y. Shan, X. Y. Peng, G. Q. Wang, X. M. Wang and J. Z. Tan, "Study on Regulation of 5' Flanking Regions of Granule-Bound Starch Synthase Gene of Potato," Acta Botanica Sinica, Vol. 40, 1998, pp. 796-800.

[57] R. G. Visser, A. Stolte and E. Jacobsen, "Expression of a

\section{Abbreviations:}

ELISA - enzyme-linked immunosorbent assay; TSPtotal soluble protein; niv-near-isogenic variety; A-nivAlbatros near-isogenic variety; D-niv-Desiree near-isogenic variety; DM-dry matter; $\mathrm{cA}$ - crude ash; $\mathrm{cP}$ -
Chimaeric Granule-Bound Starch Synthase-GUS Gene in Transgenic Potato Plants," Plant Molecular Biology, Vol. 17, 1991, pp. 691-699.

[58] H. Mikschofsky, "Charakterisierung des Produktionssystem Pflanze für die rekombinante Impfstofferzeugung," 2006.

[59] M. T. Chan and S. M. Yu, "The 3 ' Untranslated Region of a Rice Alpha-Amylase Gene Functions as a Sugar-Dependent MRNA Stability Determinant," Proceedings of the National Academy of Sciences of the United States of America, Vol. 95, 1998, pp. 6543-6547. doi:10.1073/pnas.95.11.6543

[60] Z. Zou, C. Eibl and H. U. Koop, "The Stem-Loop Region of the Tobacco Psba 5' Utr is an Important Determinant of Mrna Stability and Translation Efficiency," Molecular Genetics and Genomics, Vol. 269, 2003, pp. 340-349.

[61] H. Mikschofsky, M. Hammer, P. Konig, G. Keil, H. Schirrmeier and I. Broer, "Plant Made Veterinary Vaccines against RHD," Journal of Biotechnology, Vol. 131, No. 2, 2007, p. 44. doi:10.1016/j.jbiotec.2007.07.071

[62] M. Filipecki, Z. M. Yin, A. Wisniewska, M. Smiech, R. Malinowski and S. Malepszy, "Tissue-Culture-Res-ponsive and Autotetraploidy-Responsive Changes in Metabolic Profiles of Cucumber (Cuicumis Sativus L.)," Journal of Applied Genetics, Vol. 47, 2006, pp. 17-21.

[63] H. Rischer and K. M. Oksman-Caldentey, "Unintended Effects in Genetically Modified Crops: Revealed by Metabolomics," Trends in Biotechnology, Vol. 24, 2006, pp. 102-104. doi:10.1016/j.tibtech.2006.01.009

[64] S. M. Jain, "Tissue Culture-Derived Variation in Crop Improvement," Euphytica, Vol. 118, 2001, pp. 153-166.

[65] G. S. Catchpole, M. Beckmann, D. P. Enot, M. Mondhe, B. Zywicki, J. Taylor, N. Hardy, A. Smith, R. D. King, D. B. Kell, O. Fiehn and J. Draper, "Hierarchical Metabolomics Demonstrates Substantial Compositional Similarity between Genetically Modified and Conventional Potato Crops," Proceedings of the National Academy of Sciences of the United States of America, Vol. 102, 2005, pp. 14458-14462. doi:10.1073/pnas.0503955102

[66] P. Janczyk, C. Wolf, A. Hartmann, P. Junghans, M. Schwerin and W.-B. Souffrant, "Modification of Potatoes, by either Recombinant DNA Technology or Conventional Breeding, Affects their Nutritional Value for the Rat," Archiva Zootechnica, Vol. 10, 2007, pp. 8-21.

crude protein; $\mathrm{cF}$ - crude fibre; EE - ether extract; NfE - nitrogen-free extract; TTtPD - total tract crude protein; NPU — net protein utilization; PER - protein efficiency ratio; vs-versus. 